\title{
Área de polígonos: uma análise do material de apoio ao currículo do estado de São Paulo
}

\author{
RODRIGO RODOLFO BALTAZAR SOUZA ${ }^{1}$ \\ PAULO CÉSAR OLIVEIRA ${ }^{2}$
}

\begin{abstract}
Resumo
Este artigo é um relato de pesquisa desenvolvido no âmbito do Grupo de Estudos e Planejamento de Aulas de Matemática (GEPLAM) da UFSCar (campus Sorocaba), e tem como objetivo analisar o conteúdo Área de Polígonos contido no material de apoio ao Currículo do Estado de São Paulo, no caso, o segundo volume do Caderno do Aluno para o $8^{\circ}$ ano do Ensino Fundamental. $O$ aporte teórico utilizado foi a teoria dos registros de representação semiótica de Raymond Duval. Nosso estudo foi de natureza qualitativa na modalidade documental, cujo resultado da análise do referido material revelou a predominância da apreensão operatória na modalidade mereológica, em coordenação com outros tipos de registros.
\end{abstract}

Palavras-Chave: Área; Semiótica; Material Didático.

\begin{abstract}
This article is a research report developed in the scope of the GEPLAM (Grupo de Estudos $e$ Planejamento de Aulas de Matemática) of UFSCar (Campus Sorocaba), and aims to analyze the Polygon Area content of the support material to the Curriculum of the State of São Paulo, in this case, the second volume of the Student Book for the 8th grade of Elementary School. The theoretical basis used was Raymond Duval's theory of semiotic representation records. Our study was of qualitative nature in the documentary modality, whose result of the analysis of referred material revealed the predominance of the operative apprehension in the mereological modality, in coordination with other types of records.
\end{abstract}

Keywords: Area; Semiotics; Didactic Material.

\section{Introdução}

Este artigo traz um relato de pesquisa desenvolvido no âmbito do Grupo de Estudos e Planejamento de Aulas de Matemática (GEPLAM) da UFSCar (campus Sorocaba) na linha de pesquisa envolvendo os registros de representação semiótica sob a perspectiva de Raymond Duval. Com base no artigo publicado por Santos e Curi (2010) que teve como objetivo analisar a Proposta Curricular para o Ensino de Matemática (SÃO PAULO, 1997), no tocante às noções de área e perímetro; analisamos a abordagem conteúdo área de figuras planas no segundo volume para o $8^{\circ}$ ano do Ensino

\footnotetext{
1 Colégio Poitécnico de Sorocaba / professor de ensino fundamental II - e-mail: prof.rodrigobaltazar@gmail.com.

${ }_{2}^{2}$ Departamento de Física, Matemática e Química, área de Educação matemática/UFSCAR/Campus de Sorocaba - e-mail: pauloolliver@ig.com.br.
} 
Fundamental do Caderno do Aluno (SÃO PAULO, 2014-2017).

Santos e Curi (2010, p.32) concluíram que a "Proposta Curricular fornecia 'modelos de atividades' para subsidiar o trabalho docente, ajudando o professor no momento de suas escolhas, ou seja, indicando um caminho de como as noções de área e perímetro poderiam ser trabalhadas em cada série".

Um modelo de atividade daquela época vigente inclusive no referido Caderno do Aluno (SÃO PAULO, 2014-2017, v.2, $8^{\circ}$ ano) é a apresentação de "uma sequência para a construção da fórmula das áreas do paralelogramo, triângulo e trapézio" (SANTOS; CURI, 2010, p.31), de acordo com a Figura 1.

Figura 1: Sequência para construção de áreas de figuras planas área do papalelogramo
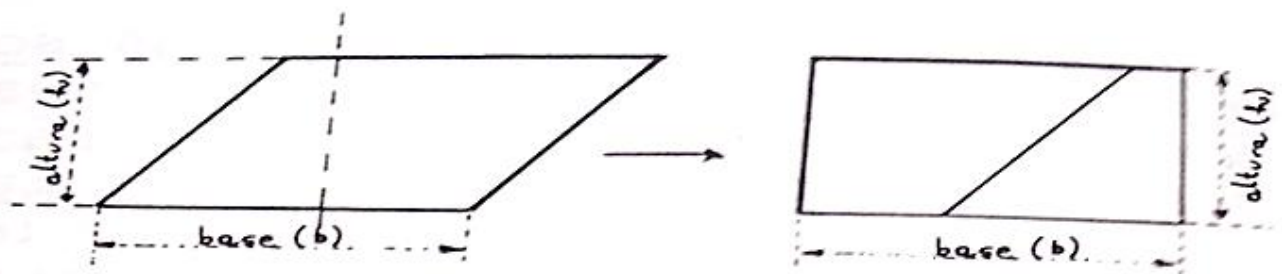

$$
A=b \times h
$$

área do triângulo
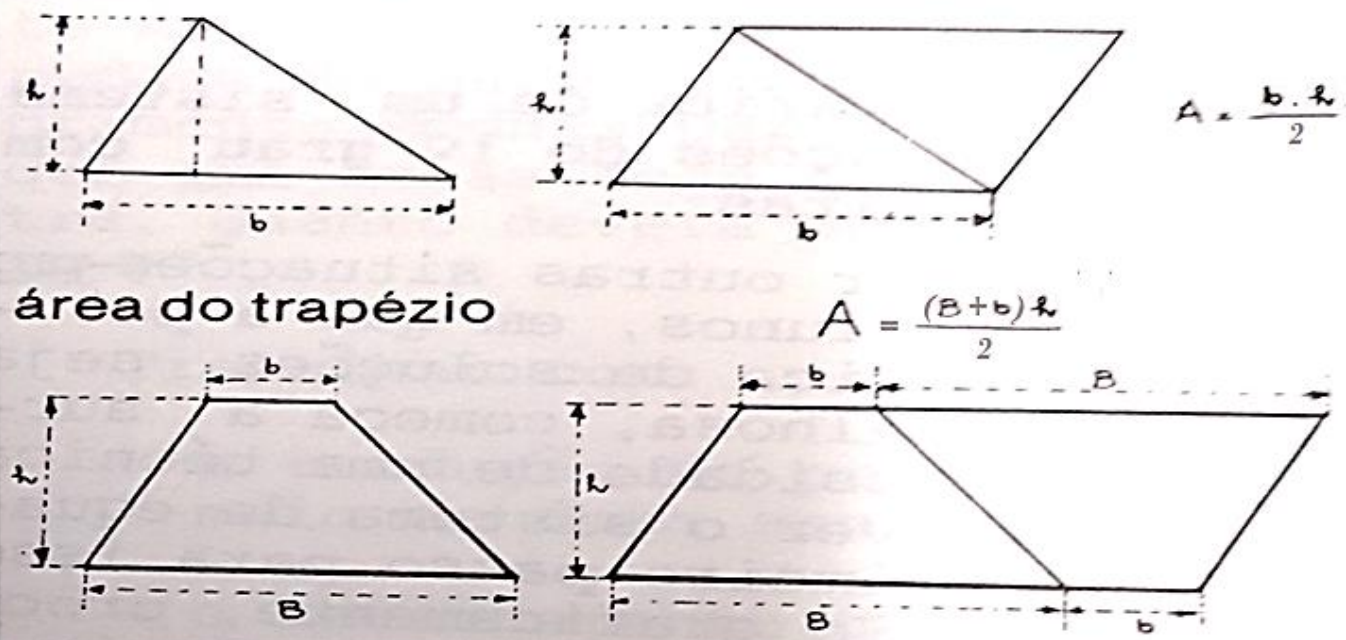

Fonte: São Paulo (1997, p.134).

Como pode ser observado na Figura 1, Santos e Curi (2010) destacaram que na $7^{\mathrm{a}}$ série (atual $8^{\circ}$ ano) eram previstos a resolução de problemas aplicados à sistematização das 
áreas do paralelogramo, triângulo, trapézio, losango, circulo e o setor circular. $\mathrm{Na}$ Proposta Curricular (SÃO PAULO, 1997, p.134) havia orientações para o professor evitar o excesso de 'algebrismo', conforme indicativo: "como a área do losango ainda não foi abordada, convém fazer um trabalho experimental precedendo a sua fórmula".

O trabalho experimental consistia na "transformação de um losango em um paralelogramo, que no momento já teve seu cálculo de área estudado. Indica como é possível o professor introduzir a nova noção com base na noção estudada anteriormente e assim pela decomposição do losango em um paralelogramo chega a sua fórmula" (SANTOS; CURI, 2010, p.31).

Em síntese, Santos e Curi (2010, p.33) consideraram que a Proposta Curricular para o Ensino de Matemática (SÃO PAULO, 1997) apresentava um caminho a ser seguido pelos professores, com possibilidades de articulação de conteúdos, "necessitando assim do aproveitamento dos conhecimentos prévios dos educandos".

Nossa pesquisa teve como propósito analisar historicamente no movimento curricular da educação paulista, se essa abordagem via minimização do "algebrismo" foi mantida ou não no estudo do conceito de área de figuras planas.

Historicamente, houve uma lacuna de vinte anos na educação paulista para a ocorrência de uma nova Proposta Curricular para o Estado de São Paulo (SÃO PAULO, 2008) que desencadeou um movimento curricular gerando um dos materiais de apoio ao Currículo do Estado de São Paulo (SÃO PAULO, 2012), o denominado Caderno do Aluno (SÃO PAULO, 2014-2017), nosso objeto de análise.

Na sequência dedicamos a apresentar esse movimento histórico até os dias atuais, de modo que o leitor possa compreender que foco de análise nessa pesquisa é parte do conteúdo do segundo volume para o $8^{\circ}$ ano (antiga $7^{\text {a }}$ série) do Ensino Fundamental.

\section{Da Proposta Curricular ao Caderno do Aluno: apontamentos históricos}

O atual Currículo do Estado de São Paulo (SÃO PAULO, 2012) iniciou seu processo de consolidação a partir da nova Proposta Curricular do Estado de São Paulo (SÃO PAULO, 2008).

Passados vinte anos entre a Proposta Curricular analisada por Santos e Curi (2010) e esse novo documento publicado em 2008, em termos educacionais, houve uma mudança 
na concepção de escola como uma instituição que ensina para uma escola que precisa aprender a ensinar. De acordo com esta concepção há uma ruptura no papel do professor como detentor do conhecimento em prol de que o conhecimento coletivo é maior do que a soma dos conhecimentos individuais (COBELLO; OLIVEIRA, 2015).

Na nova Proposta Curricular para a educação paulista optou-se por uma educação centrada em competências, ou seja, a escola e o plano do professor devem indicar o que aluno vai aprender. Uma das razões pela escolha desta concepção é a democratização da escola, ou seja, a escola deve "tem de ser igualmente acessível a todos, diversa no tratamento de cada um e unitária nos resultados" (SÃO PAULO, 2008, p.15).

Em virtude da importância da linguagem no desenvolvimento da criança e do adolescente, priorizou-se a competência de leitura e escrita nessa Proposta Curricular (SÃO PAULO, 2008). Para desenvolvê-la era indispensável que fosse objetivo de aprendizagem de todas as disciplinas do currículo, ao longo de toda a escolaridade básica.

No que diz respeito à Matemática, além dos três blocos temáticos (números, geometria, medidas) já contemplados na Proposta Curricular (SÃO PAULO, 1997), um quarto bloco, denominado Tratamento da Informação completou a atualização curricular da nova Proposta Curricular (SÃO PAULO, 2008) e abriu espaço para a incorporação crítica das tecnologias no ensino.

O atual Currículo do Estado de São Paulo - CESP (SÃO PAULO, 2012) cuja primeira edição foi publicada em 2010, contém um texto similar à Proposta Curricular (SÃO PAULO, 2008); exceto pelo reagrupamento de conteúdos devido à retirada do bloco temático denominado Tratamento da Informação. Argumentou-se no CESP que tem sido frequente rotular conteúdos de estatística descritiva como Tratamento da Informação, porém, considera-se "necessário evidenciar aqui o fato de que todos os conteúdos estudados na escola básica, em todas as disciplinas, podem ser classificados como ‘Tratamento da Informação' ’(SÃO PAULO, 2012, p.36).

Neste sentido, não havia um porquê de agrupar um determinado conjunto de conteúdos da disciplina de Matemática em um bloco temático com a referida denominação, já que “a transformação da informação em conhecimento, é a meta comum de todas as disciplinas escolares e, em cada disciplina, de todos os conteúdos a serem ensinados" (SÃO PAULO, 2010, p.36). 
Em 2009, logo após a implantação da nova Proposta Curricular (SÃO PAULO, 2008), as escolas públicas estaduais começaram a receber bimestralmente quatro volumes bimestrais de cada componente curricular do Ensino Fundamental II e Médio, repassados para os estudantes, no caso, o Caderno do Aluno e, para os docentes, o Caderno do Professor.

A partir de 2014, para ajustar a logística de distribuição do material de apoio ao Currículo do Estado de São Paulo (SÃO PAULO, 2012), o Caderno do Professor e do Aluno, os mesmos foram reeditados, mantendo o mesmo conteúdo, passando de quatro volumes para dois volumes, um por semestre letivo.

Cada volume do Caderno do Professor contém as Situações de Aprendizagem para orientar o trabalho do professor no ensino dos conteúdos disciplinares específicos e a aprendizagem dos alunos. Esses conteúdos, habilidades e competências são organizados por série/ano e acompanhados de orientações para a gestão da aprendizagem em sala de aula e para a avaliação e recuperação. Oferecem também sugestões de métodos e estratégias de trabalho para as aulas, experimentações, projetos coletivos, atividades como lição de casa e estudos interdisciplinares.

No Caderno do Aluno são apresentadas as aulas conforme o Caderno do Professor, contendo as tarefas, textos complementares, indicadores bibliográficos, dicas de estudo e revisão.

O Currículo do Estado de São Paulo (SÃO PAULO, 2012) foi organizado com os conteúdos matemáticos distribuídos em três blocos temáticos: Números, Relações e Geometria. No bloco 'Relações', “o ponto de partida natural é o estudo das medidas: medir e comparar uma grandeza com um padrão é expressar o resultado da comparação por meio de um número" (SÃO PAULO, 2012, p.43).

O bloco Geometria está relacionado diretamente:

[...]à percepção de formas e de relações entre elementos de figuras planas e espaciais; à construção e à representação de formas geométricas, existentes ou imaginadas, e à elaboração de concepções de espaço que sirvam de suporte para a compreensão do mundo físico que nos cerca. (SÃO PAULO, 2012, p. 39)

O cálculo de áreas se inicia pela contagem de quadrados como unidade de medida e culmina com a sua formalização em expressões literais que traduzem medidas e 
relações entre as mesmas.

Nesse documento há dois momentos em que se privilegia o estudo do conceito de área, conforme exposição no quadro1.

Quadro 1: Conteúdos e habilidades envolvendo área de polígonos no Ensino Fundamental

\begin{tabular}{|l|l|}
\hline \multicolumn{2}{|c|}{$\mathbf{3}^{\mathbf{0}}$ bimestre do $\mathbf{6}^{\mathbf{0}}$ ano } \\
\hline \multicolumn{1}{|c|}{ Conteúdos } & \multicolumn{1}{c|}{ Habilidades } \\
\hline $\begin{array}{l}\text { Unidade de medida, perímetro, cálculo de } \\
\text { área por composição e decomposição, } \\
\text { resolução de problemas. }\end{array}$ & $\begin{array}{l}\text { Compreender a noção de área e perímetro de } \\
\text { uma figura, sabendo calculá-los por meio de } \\
\text { recursos de contagem e de decomposição de } \\
\text { figuras. }\end{array}$ \\
\hline \multicolumn{1}{|c|}{$\mathbf{4}^{\mathbf{0}}$ bimestre do 8 ano } \\
\hline Área & $\begin{array}{l}\text { Calcular áreas de polígonos de diferentes } \\
\text { tipos, com destaque para os polígonos } \\
\text { regulares }\end{array}$ \\
\hline
\end{tabular}

Fonte: SÃO PAULO (2012)

No presente artigo apresentamos uma análise da noção de área de polígonos abordada no oitavo ano, pelo fato de ser o momento escolar que há ênfase nas expressões literais envolvidas neste conteúdo.

Na sequência abordamos o referencial teórico-metodológico dessa pesquisa, os registros de representação semiótica na perspectiva de Raymond Duval. Caracterizamos este aporte teórico como metodológico devido às categorias a priori extraídas da teoria para serem utilizadas na análise documental do segundo volume do Caderno do Aluno.

\section{Registros de Representação Semiótica e a Geometria}

A semiótica é "a ciência que tem por objeto de investigação todas as linguagens possíveis, ou seja, que tem por objetivo o exame dos modos de constituição de todo e qualquer fenômeno como fenômeno de produção de significado e sentido" (SANTAELLA, 2002, p.13). No caso da matemática, a comunicação extrapola o uso da língua materna, principalmente via registros escritos; pois nos comunicamos também por meio de gráficos, tabelas, simbologias algébricas, figuras geométricas, entre outras formas de registros de representação semiótica.

A teoria dos Registros de Representação Semiótica de Raymond Duval (2009, 2014) é um dos pilares teóricos-metodológicos utilizados nas produções acadêmicas vinculadas ao GEPLAM, por concentrar seus estudos na aprendizagem da matemática, segundo os 
aspectos cognitivos para a compreensão da mesma. Do ponto de vista cognitivo, o processo de aprendizagem requer a mobilização de diferentes registros semióticos de representação para que não haja confusão entre o objeto matemático e a representação do mesmo, bem como, a coordenação entre os diferentes registros.

Duval (2009) afirma que não é possível estudar os fenômenos relativos ao conhecimento sem se recorrer à noção de representação. A natureza dessa representação é semiótica pelo fato de que o signo comumente relacionado com objeto concreto, no caso da matemática associa-se ao símbolo. Este, por sua vez, representa o objeto abstrato por meio da ação do sujeito do conhecimento (significante ou conceito).

O termo abstrato diz respeito ao fato de que o objeto matemático não é perceptível, mas seu acesso se dá por meio de representações semióticas. Com efeito, outro argumento se constrói, desta vez em relação ao binômio objeto-representação: "não se pode ter compreensão em matemática, se nós não distinguimos um objeto de sua representação" (DUVAL, 2009, p14).

Há uma ênfase para a necessidade de não confundir os objetos matemáticos com suas representações, pois diversas representações podem estar associadas ao mesmo objeto matemático. No caso de área de figura plana podemos defini-la como o espaço ocupado por uma superfície (registro na língua natural). Esta forma de representação semiótica difere da noção de área como processo de contagem do número de ladrilhos necessários para recobrir uma superfície (registro numérico). Podemos exibir uma terceira representação semiótica diferente em seu conteúdo das anteriores que é a noção de área associada à expressão algébrica de acordo com a figura plana em questão (registro algébrico).

A teoria dos registros de representação desenvolvida por Raymond Duval estabelece que, para um indivíduo desenvolver o funcionamento do seu pensamento na aquisição de um conhecimento matemático é necessário tanto diferenciar uma noção científica dos registros semióticos que a representam, quanto conhecer a funcionalidade desses registros. Neste contexto, ocorre no funcionamento cognitivo do pensamento humano, aquisições funcionais relativas tanto aos sistemas orgânicos, disponíveis desde o nascimento, como a audição, a visão, o tato e a memória; quanto aos sistemas semióticos, usados para se comunicar e também para organizar e tratar as informações.

Com isso, numa atividade de aquisição de conhecimento matemático, tem que ser 
levados em conta dois componentes: os seus próprios conteúdos, nos quais existem métodos e processos para descobrir e estabelecer resultados e, o cognitivo, que segundo Duval (2009), a identificação de uma noção matemática com seus registros de representação semióticos pode constituir-se num dos problemas centrais da aprendizagem dessa noção.

Um registro de representação semiótico de um objeto matemático pode ser um símbolo, uma figura ou a língua natural. Cada tipo de registro apresenta um conteúdo diferente estabelecido pelo sistema no qual ele foi produzido.

A apreensão das características diferentes só terá sucesso quando o indivíduo que aprende for capaz de efetuar transformações nos registros. Pode ser na forma de tratamento que são operações internas a um mesmo registro, como por exemplo, representar um quadrado com as sete peças do Tangram. Outro modo diz respeito à coordenação de registros que garantam a atividade de conversão que consiste na passagem de um registro a outro, com mudança na forma pela qual determinado registro é representado. Por exemplo: com base na construção de polígonos em uma malha quadriculada, podemos utilizar a fórmula de Pick para expressar o cálculo da área por meio da contagem do número de pontos no perímetro e o número de pontos no interior do polígono (DUVAL, 2009).

Desse modo, quando o aluno é capaz de coordenar espontaneamente os vários registros de representação de um mesmo objeto, significa que ocorreu de fato uma aprendizagem de determinado conceito, no caso, a área.

Na sequência dedicamos a descrever conceitos que se referem às apreensões figurais, com o objetivo de subsidiar a análise da produção de informação desta pesquisa.

\section{Os registros de representação semiótica em geometria}

As tarefas escolares em geometria apresentam grande originalidade em relação aos demais ramos da matemática por dois motivos: por um lado, os problemas de geometria exigem uma forma de expressão intermediária entre a língua natural e a linguagem matemática; devido a forma de raciocínio ligada à uma axiomática que se desenvolve pelo registro da língua natural. "Por outro lado, a heurística de problemas de geometria refere-se a um registro de representações espaciais que originam formas de interpretações autônomas": apreensões perceptiva, operatória, discursiva e sequencial 
das figuras. (DUVAL, 2012, p.119)

A resolução de tarefas em geometria depende da conscientização da oposição entre as formas de apreensão perceptiva, operatória e discursiva das figuras. Seja qual for a figura desenhada no contexto de uma atividade matemática, ela é objeto de duas atitudes geralmente contrárias: a apreensão perceptiva que é o reconhecimento visual imediato da forma e outra controlada, que torna possível a aprendizagem; a apreensão (interpretação) discursiva dos elementos figurais.

Uma figura segundo Duval (2011, p.91) "é identificada pelas propriedades que não vemos porque nenhum desenho as mostra em sua generalidade. Essas propriedades só podem ser aprendidas por conceitos, isto é, os termos definidos nos enunciados". O desenho (expressão gráfica), por sua vez, é uma "configuração particular que se mostra no papel, no quadro negro ou no papel do computador".

Os elementos figurais podem ser representações visuais tridimensionais (cubo, pirâmide, esfera, entre outros), bidimensionais (polígonos, círculos, entre outros), unidimensionais (retas, curvas, entre outras) ou adimensionais (pontos notáveis como vértice, intersecção ou extremidade). A interpretação discursiva destes elementos figurais deve ser feitas através ou em função das propriedades, ou das condições formuladas como hipóteses, tomando por base o conteúdo do enunciado. No entanto, Duval (2012, p.123) adverte uma atitude comum dos alunos diante de uma tarefa geométrica: "eles leem o enunciado, constroem a figura e, em seguida, concentram-se na figura sem retornar ao enunciado".

Esta advertência reforça o fato de que uma transformação de registro, em geometria; não envolve apenas a mudança de registro. É necessário que os tratamentos figurais e discursivos se efetuem simultaneamente e de maneira interativa, ou seja, deve haver uma coordenação entre nas transformações de representações semióticas envolvendo os tratamentos realizados na língua natural e na figura.

A apreensão operatória depende das modificações que uma figura pode sofrer:

a) Mereológica: envolve a operação de reconfiguração que consiste no fracionamento de uma figura inicial que são subfiguras da figura dada;

b) Ótica: envolve a transformação de uma figura em outra considerada imagem;

c) Posicional: trata-se do deslocamento ou rotação em relação a um referencial. 
No caso da apreensão mereológica, podemos citar a reconfiguração como procedimento para o cálculo das áreas de figuras planas. No caso ótico temos a homotetia como exemplo e, na apreensão posicional podemos citar as propriedades de simetria em figuras planas.

A apreensão sequencial é explicitamente solicitada em atividades de construção ou em atividades de descrição, tendo por objetivo a reprodução de uma dada figura.

Em síntese, Duval (2014, p.37) afirma que o acesso aos objetos matemáticos, inclusive geométricos, "não é jamais empírico, é semiótico, o que não quer dizer teórico. Isto significa que a atividade matemática exige a utilização de muitos sistemas de representação semióticos e, também, a língua natural, mesmo que não sirva para calcular" (itálico do autor). No decorrer da atividade geométrica há um diálogo contínuo entre visualização (registro figural) e o discurso (registro na língua natural).

\section{Análise da Situação de Aprendizagem no Caderno do Aluno}

Cada volume do Caderno do Aluno e do Professor é composto por oito Situações de Aprendizagem. No caso do Caderno do Professor há um roteiro para a aplicação de cada Situação de Aprendizagem e na sua introdução encontramos o conteúdo que será abordado, as competências e habilidades desenvolvidas e sugestões de estratégias para se aplicar em sala de aula.

Para o propósito de nossa pesquisa os conteúdos e temas envolvidos nesse Caderno do Professor são: "áreas de figuras planas representadas em malhas, áreas de triângulos e quadriláteros". As competências e habilidades envolvem a estimativa de "áreas de figuras regulares e irregulares; compreender diferentes processos de cálculos de áreas; aplicar fórmulas para cálculo de áreas de polígonos; identificar os termos necessários ao cálculo da área de um polígono". Finalmente, “compor e decompor figuras planas, resolução de situações-problema", são as sugestões de estratégias pedagógicas (SÃO PAULO, 2014-2017, v.2, $8^{\circ}$ ano, p.70).

No respectivo Caderno do Aluno o desenvolvimento do conteúdo área de polígonos contemplou equivalência de figuras planas, Fórmula de Pick (cálculo de áreas por contagem), áreas de figuras irregulares e as fórmulas das áreas de figuras planas (SÃO PAULO, 2014-2017, v.2, $8^{\circ}$ ano), as quais analisamos na sequência, tomando por base as apreensões geométricas. 
$\mathrm{Na}$ leitura e análise de texto disponibilizado para a abordagem da equivalência de figuras planas nota-se a representação figural caracterizada pela modificação mereológica. A divisão do quadrado (Figura 2) em duas subfiguras (retângulo) ao ser reorganizadas formou um retângulo com área equivalente ao quadrado inicial, ou seja, esse retângulo é uma subfigura do quadrado apresentado.

Figura 2: Modificação Mereológica na Equivalência de Figuras
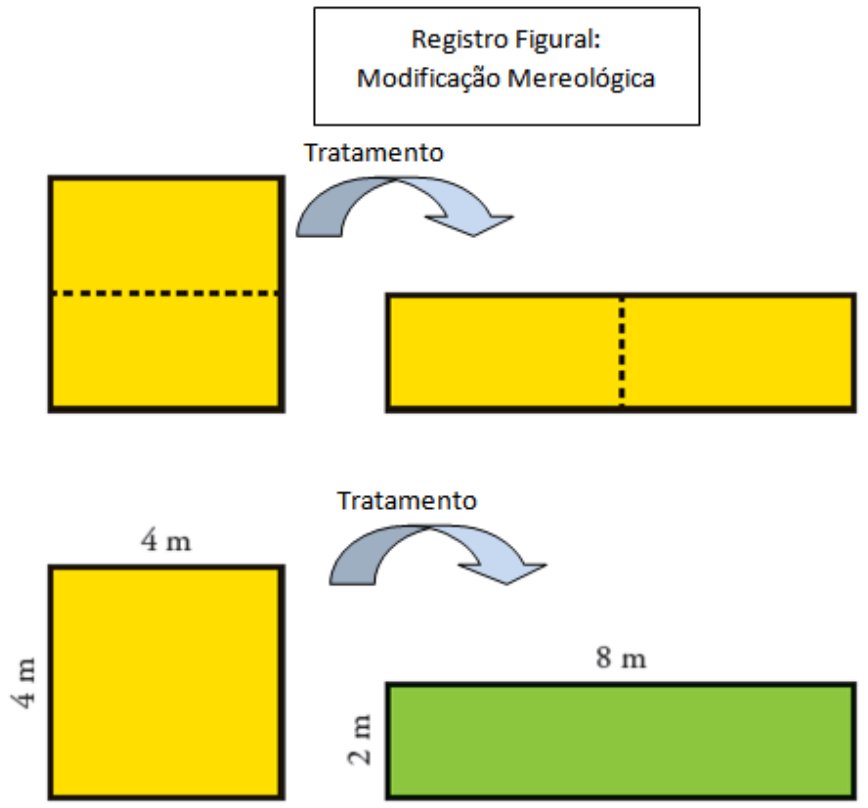

Fonte: Caderno do Aluno (SÃO PAULO, 2014-2017, v.2, $8^{\circ}$ ano, p. 64).

Na sequência o material propõe três atividades para os alunos. A seguir são apresentadas as sínteses das atividades que são propostas aos alunos, para que os mesmo apliquem as ideias discutidas na Situação de Aprendizagem.

A Atividade 1 apresenta um problema, no qual o aluno deve encontrar o paralelogramo com um único corte transversal, cuja área seja equivalente ao hexágono apresentado. Para a resolução desse problema parte-se da representação figural e utiliza-se a apreensão operatória via modificação mereológica.

$\mathrm{Na}$ atividade 2, no "item a", o aluno tem que descrever o método usado para encontrar a altura e determinar o valor da altura de um retângulo cuja base mede $50 \mathrm{~cm}$ e é equivalente a outro cujo a altura mede $80 \mathrm{~cm}$ e a base mede $125 \mathrm{~cm}$. Há instruções para que o aluno resolva o problema com base no registro na língua natural e algébrico, 
podendo ou não se utilizar também do registro figural. E por fim, no "item b", é solicitado que se compare os perímetros e descreva o que é observado. Novamente destaca-se o registro na língua natural, bem como a possibilidade de utilizar tanto o registro algébrico quanto o registro figural.

Por último, na Atividade 3, cuja finalidade é encontrar o retângulo equivalente ao retângulo com base de $16 \mathrm{~cm}$ e altura de $4 \mathrm{~cm}$, cujo o perímetro seja o menor possível, o aluno pode utilizar da representação figural com ênfase na modificação mereológica.

Um segundo texto diz respeito à fórmula de Pick, a qual é somente apresentada na sua representação algébrica. O referido Caderno do Aluno (SÃO PAULO, 2014-2017) disponibiliza uma síntese histórica de como o matemático Georg Pick obteve essa relação. A seguir apresentamos as sínteses das duas atividades que apresentam como objetivos a aplicação da fórmula de Pick.

$\mathrm{Na}$ atividade 4, o aluno deve calcular a área de três figuras: quadrado, retângulo e triângulo (Figura 3). A partir do registro figural, ele irá transcrever as informações obtidas no registro tabular de modo que seja possível obter o cálculo da área pela fórmula de Pick, ou seja, B/2 + I - 1. Na "figura 3", o valor de B diz respeito ao número de pontos no perímetro e o valor de I relaciona o número de pontos interno ao polígono, dispostos na malha quadriculada.

Figura 3: Conversão de registros de representação semiótica

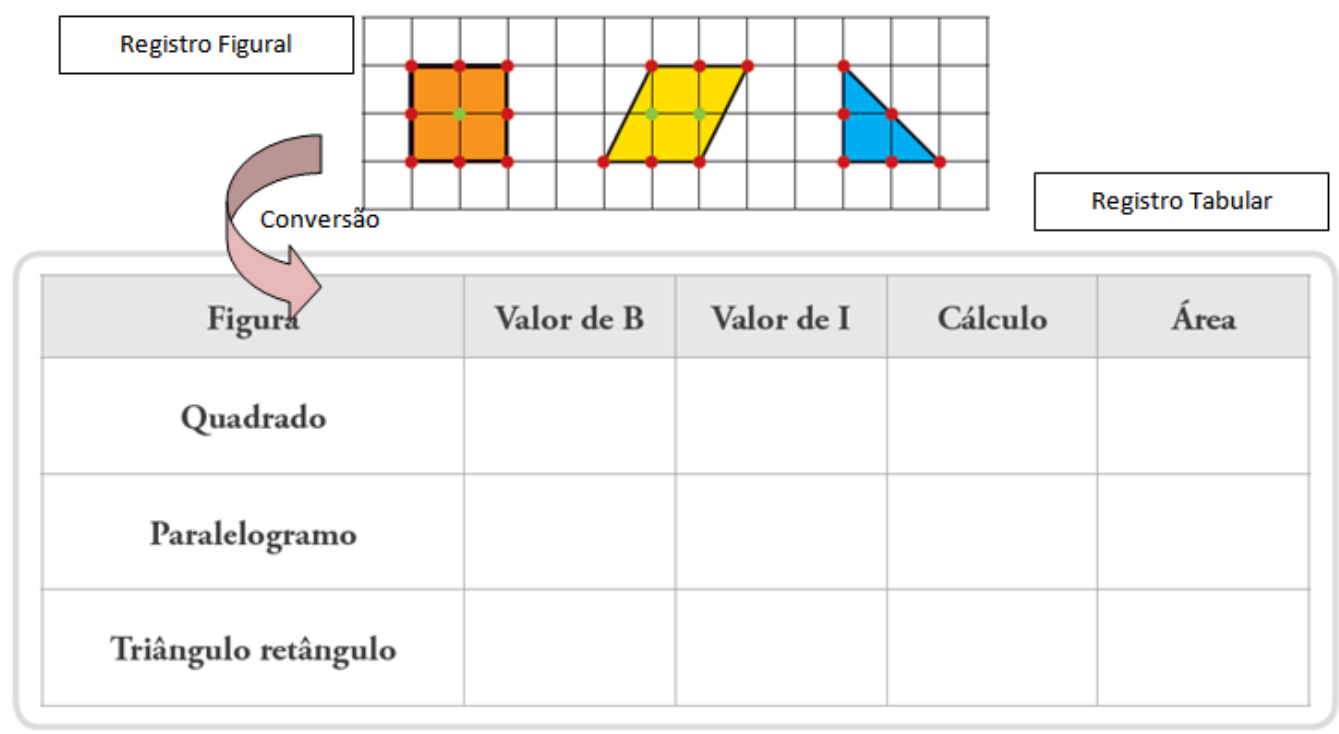

Fonte: Caderno do Aluno (SÃO PAULO, 2014-2017, v.2, $8^{\circ}$ ano, p. 66). 
Na Atividade 5 o problema proposto exige que o aluno encontre a área da figura que é apresentada em um Geoplano, aplicando a fórmula de Pick. A conversão entre a representação semiótica figural e a algébrica, na aplicação da fórmula de Pick, ocorreu apenas nesta tarefa do Caderno do Aluno (SÃO PAULO, 2014-2017, v.2, $8^{\circ}$ ano).

Em seguida é disponibilizado o terceiro texto envolvendo a noção de Aerofotogrametria para auxiliar no cálculo de área de polígonos irregulares:

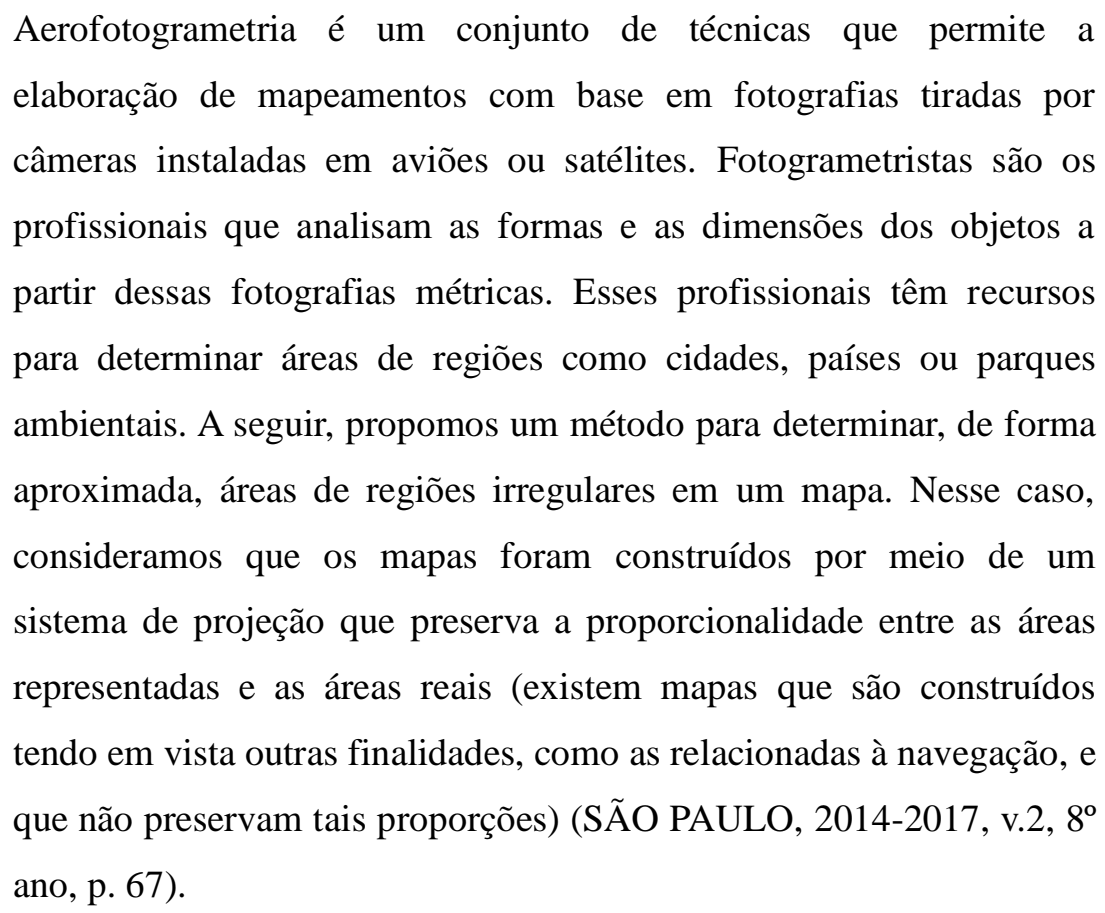

A Atividade 6, em seu enunciado, explora os procedimentos para se estimar o valor da área de polígonos irregulares, destacados e analisado com base na Figura 4.

Percebe-se a presença do registro na língua natural, algébrico e figural, este último com característica de modificação óptica, pois a figura é deformada de tal forma que só contenha quadrados completos.

Ao final dessa atividade ainda, é proposto que o aluno estime a área do estado de Minas Gerais. Sobre essa proposta ainda há uma pesquisa a ser feita, comparando a área estimada no exercício e área real do estado de Minas Gerais. Sugere-se que essa pesquisa seja realizada por meio de atlas e/ou internet.

Mais uma leitura e análise de texto é proposta, com o propósito do desenvolvimento das expressões literais que permitem o cálculo da área de alguns polígonos importantes. 
Figura 4: Procedimentos para se obter a área de um polígono irregular

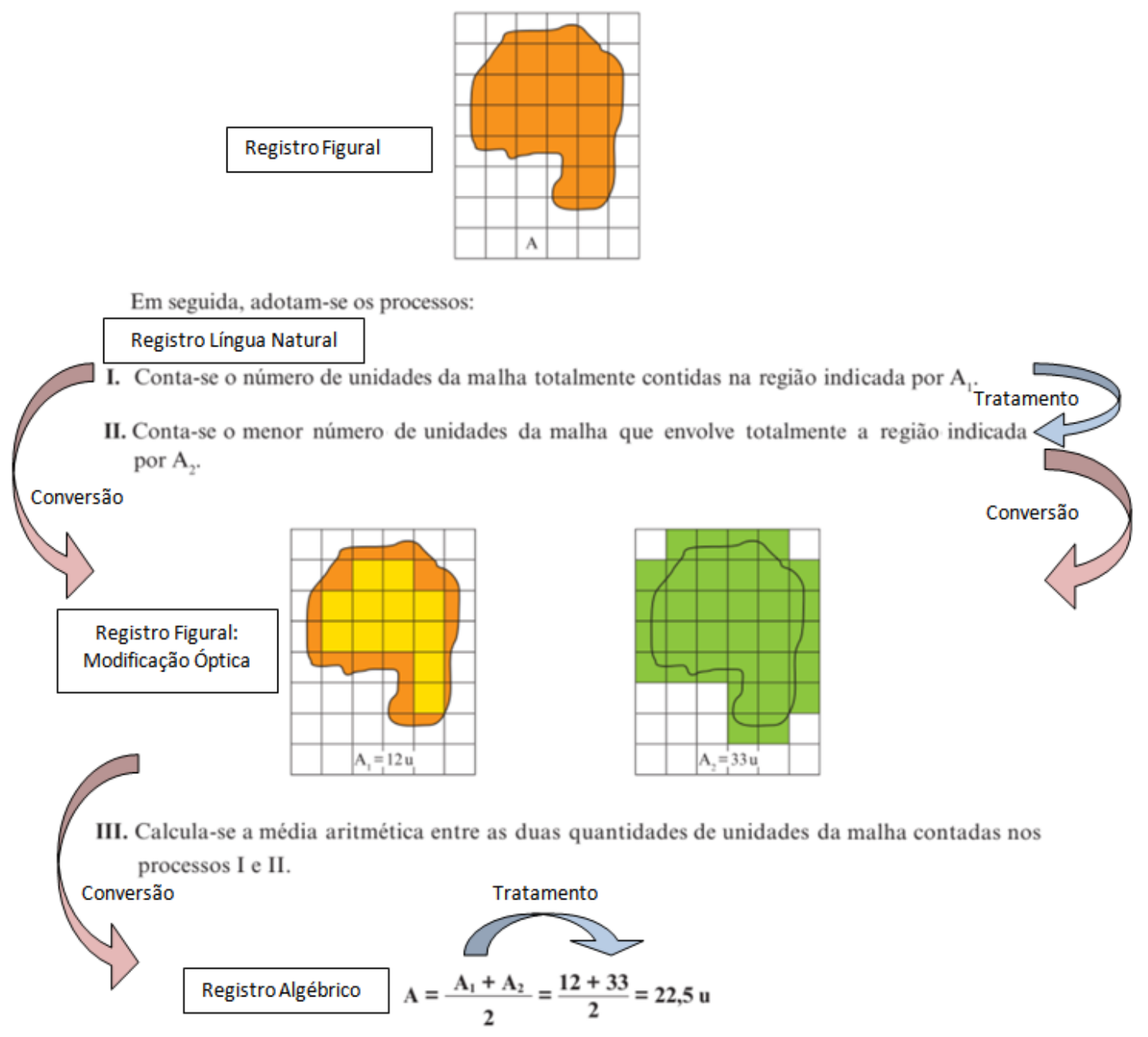

Fonte: Caderno do Aluno (SÃO PAULO, 2014-2017, v.2, $8^{\circ}$ ano, p. 68).

O primeiro polígono a ser abordado em termos de definição de área é o paralelogramo, "obtida a partir da equivalência com a área de um retângulo de base e altura, respectivamente, congruentes à base e à altura do paralelogramo considerado" (SÃO PAULO, 2014-2017, v.2, $8^{\circ}$ ano, p. 70).

A representação figural tem características da modificação mereológica, pois divide o paralelogramo em duas subfiguras, e ao reorganiza-las obtém-se um retângulo. Essa construção sofre uma transformação de conversão do registro figural em registro na língua natural, cujo conteúdo matemático explicita a fórmula da área do paralelogramo, conforme Figura 5. 
Figura 5: Área do paralelogramo: Registro de Representação e Modificação Figural

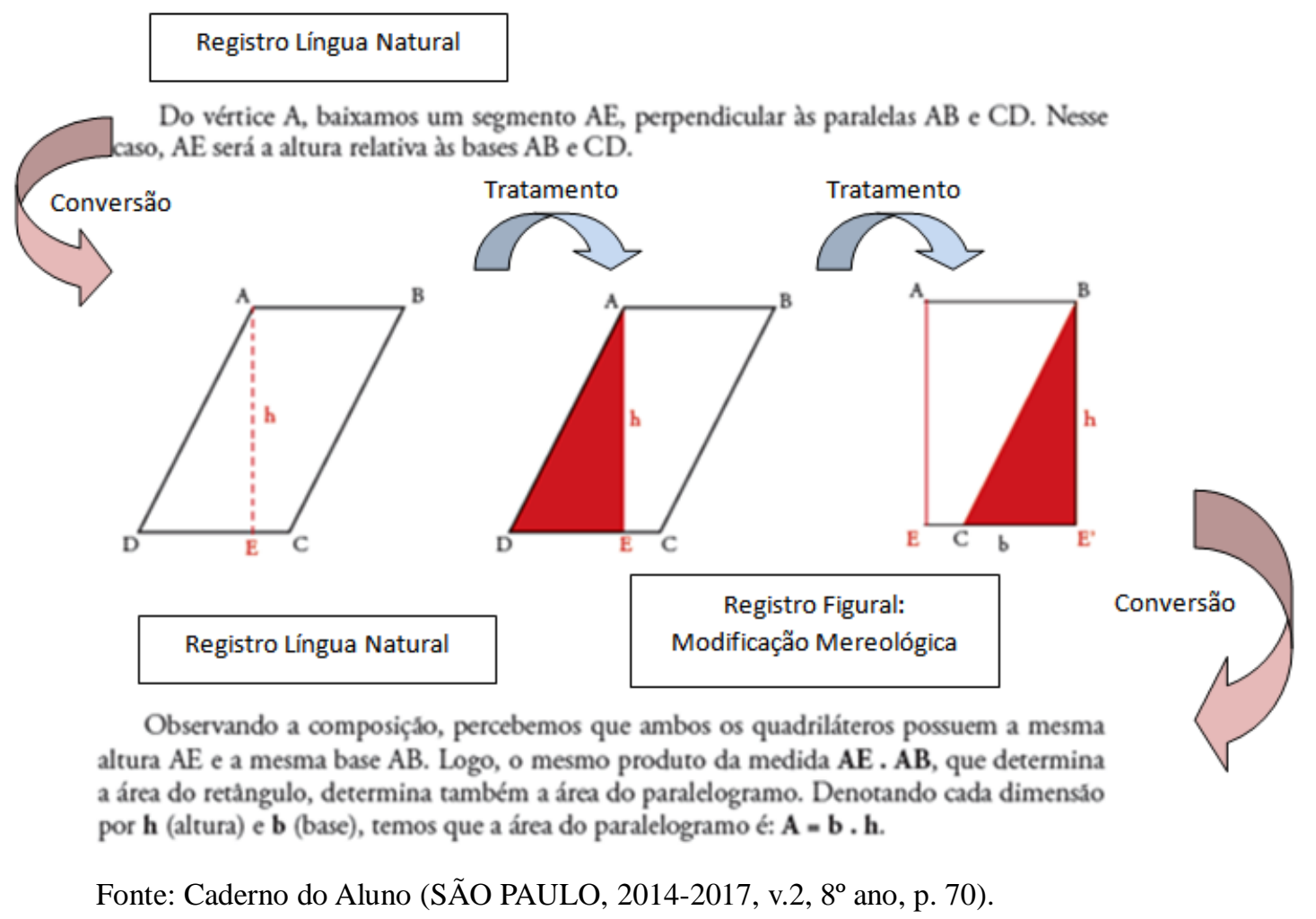

O segundo polígono a ser demonstrada a fórmula da sua área é o losango, que se inicia com uma descrição de comparação da área desse objeto matemático com a área do paralelogramo (Figura 6), via representação figural. Primeiramente observa-se a apreensão operatória via modificação posicional, pois a figura é rotacionada de tal maneira a ficar como um paralelogramo. Após este tratamento figural do registro é apresentada a fórmula da área decorrente dessa construção.

Para o segundo caso é considerado as diagonais do losango (Figura 6). Os procedimentos que desencadeiam a expressão algébrica envolvem uma apreensão operatória mereológica, pois o losango é dividido em subfiguras, e ao reorganizá-las forma-se um retângulo e, ao final, é apresentada a fórmula do losango utilizando as diagonais.

A demonstração da área do triângulo é iniciada através de uma descrição reproduzida na Figura 7. No registro figural nota-se a apreensão operatória na modificação óptica, pois pode-se considerar que a figura construida é espelhada no triângulo inicial. Novamente, pelo registro na língua natural, determina-se a fórmula da área do triângulo. 
Figura 6: Área do losango: Registro de Representação e Modificação Figural

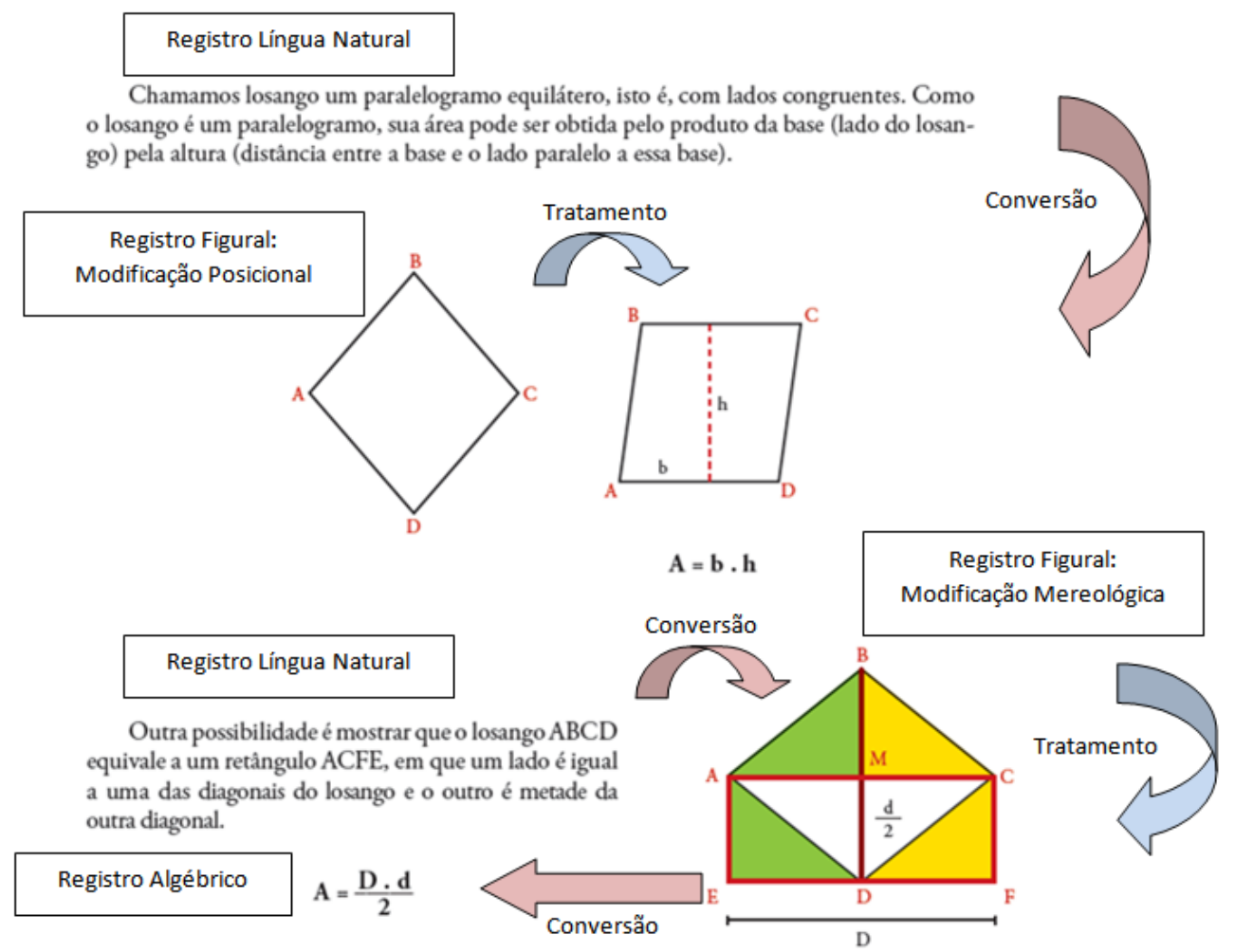

Fonte: Caderno do Aluno (SÃO PAULO, 2014-2017, v.2, $8^{\circ}$ ano, p. 71).

Figura 7: Área do Triângulo: Registro de Representações e Modificação Figural

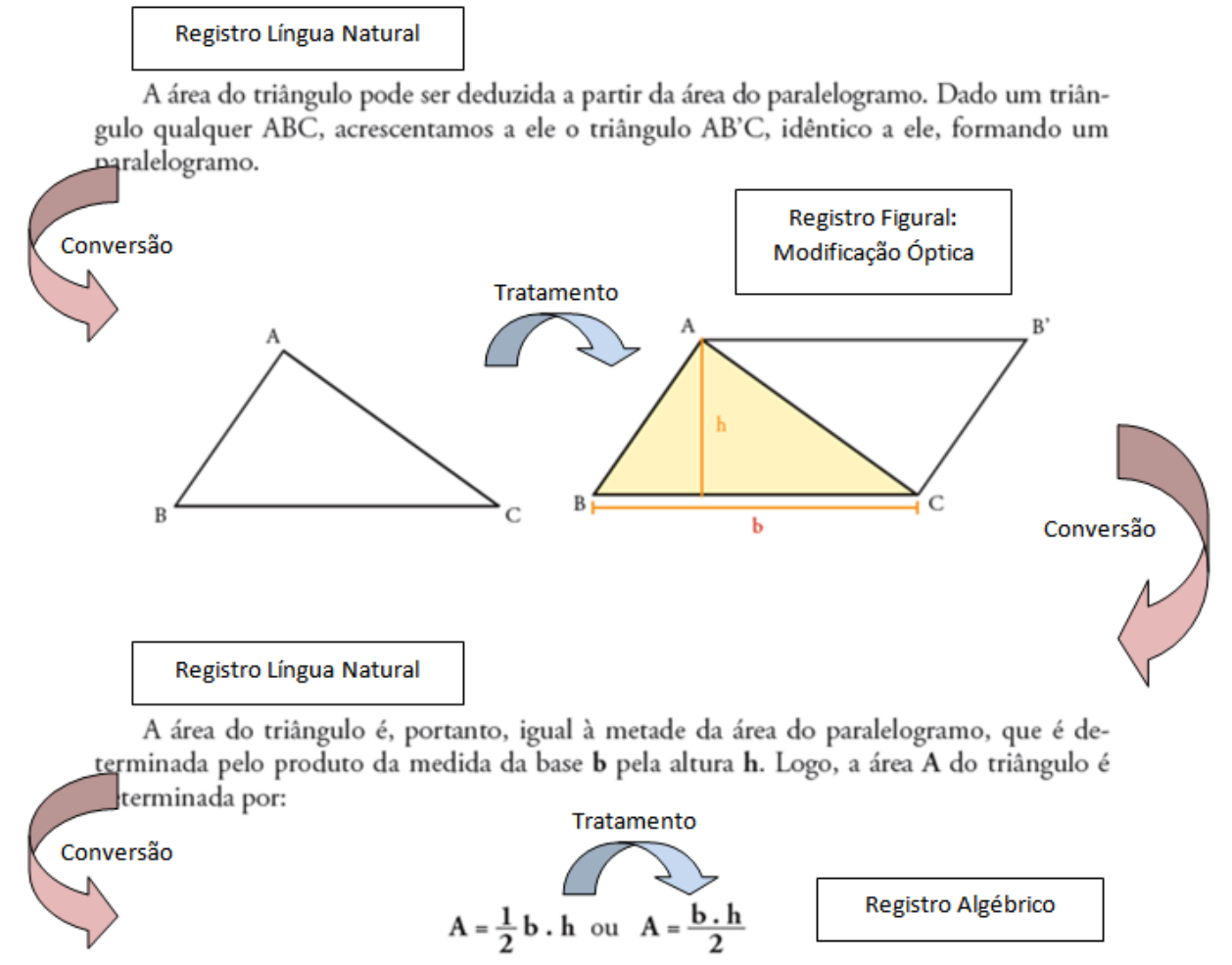

Fonte: Caderno do Aluno (SÃO PAULO, 2014-2017, v.2, $8^{\circ}$ ano, p. 72). 
A área do trapézio é deixada como desafio para o aluno. Espera-se que a partir dos trabalhos experimentais anteriores, o estudante tenha a capacidade de deduzir a fórmula deste polígono. Nesse caso, é proposto que o aluno parta da figura apresentada no enunciado da atividade para demonstrar a fórmula.

Ao final são propostas duas Atividades como Lição de Casa. A Atividade 7, apresenta um problema que propõe aplicar o cálculo de área de quadrado e retângulo para obter uma expressão algébrica, cujo enunciado apresentamos a seguir:

A figura a seguir indica uma folha de latão que será usada na montagem de uma peça (as medidas estão em metros).

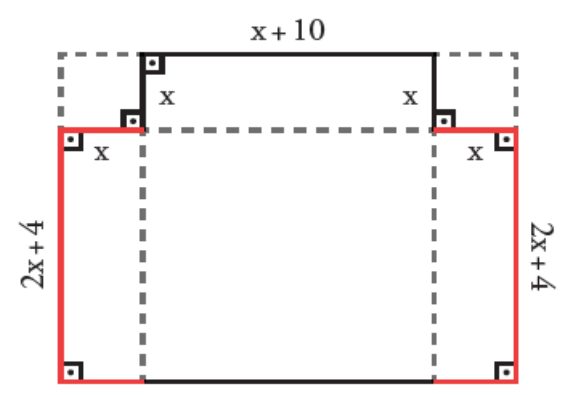

a) Se calcularmos a área da superfície da folha de latão necessária à construção da peça, ela será uma expressão que depende do valor de $\mathbf{x}$. Escreva essa expressão.

b) Encontre o valor da área dessa superfície quando $\mathrm{x}=4$ metros. (SÃO PAULO, 2014-2017, v.2, $8^{\circ}$ ano, p. 73).

Em termos de registro de representação semiótica, para obter a área da superfície da folha de latão na forma de um registro algébrico, é necessário partir da apreensão operatória mereológica, pois a figura plana foi dividida em subfiguras (três retângulos e um quadrado), e ao reorganizá-las a partir do cálculo de cada área, forma-se novamente a folha de latão (área total).

Em síntese, há uma conversão do registro figural (apreensão operatória mereológica) para o registro algébrico, cujo tratamento da escrita algébrica da área para cada uma das quatro sub-figuras, gera a área total.

Finalmente, a Atividade 8, propôs uma discussão em grupo sobre quanto vale a área da figura sobreposta a outra, conforme enunciado a seguir:

Separe duas folhas de papel sulfite. Disponha uma sobre a outra como mostra a figura a seguir. Discuta com seu colega se a folha que está 
por cima cobriu a metade, mais da metade ou menos da metade da folha que está por baixo.
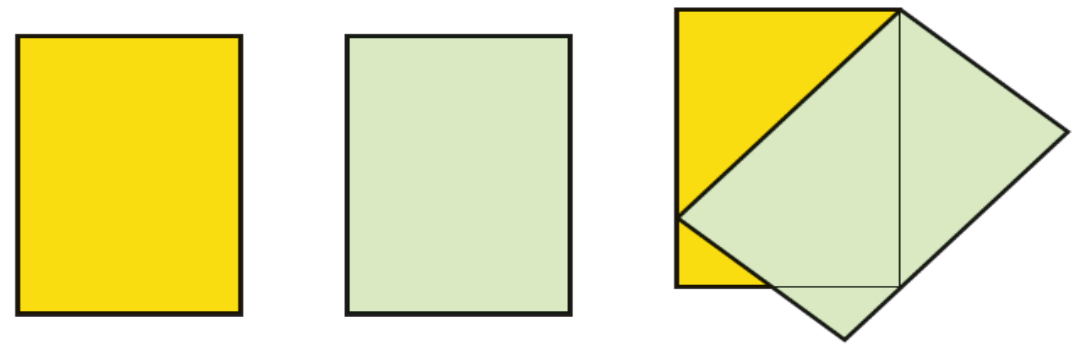

(SÃO PAULO, 2014-2017, v.2, $8^{\circ}$ ano, p. 74).

Na sobreposição da segunda folha de sulfite sobre a primeira, ocorreu uma modificação posicional, relacionada ao deslocamento e rotação sofrido pela segunda folha. É desejável que na resolução deste problema, ocorra uma conversão do registro figural para o registro da língua natural, após as interlocuções travadas entre os colegas de turma, dispostos em duplas.

Usualmente podemos considerar três modos de abordar a resolução de problemas: ensinar sobre resolução de problemas, ensinar matemática para resolver problemas e ensinar matemática através da resolução de problemas (ONUCHIC \& ALLEVATO, 2011). O primeiro modo diz respeito aos procedimentos para resolver problemas, o segundo modo concebe a resolução de problemas como aplicação de conceitos e o terceiro relaciona a resolução de problemas como meio para a construção de conceitos matemáticos.

As atividades propostas no Caderno do Aluno contemplam a resolução de problemas por possibilitar ao aluno o confronto com questões às quais não consegue responder de forma imediata, mas que o levam a refletir no como e no porque, sempre na procura da solução.

Em termos de organização desse material de apoio ao Currículo do Estado de São Paulo (SÃO PAULO, 2012) a resolução de problemas foi disposta após a sistematização do cálculo das áreas de figuras planas, como aplicação dos conceitos abordados. Tomando por base a Proposta Curricular do Estado de São Paulo (SÃO PAULO, 1997), o caminho de como as noções de área pode ser desenvolvidas em sala de aula conforme ilustrado na Figura 1 perpetua até os dias atuais evitando o excesso do "algebrismo", de acordo com o que foi exposto nas Figuras 2 a 7. 
Diante da análise documental do conceito de área no Caderno do Aluno (SÃO PAULO, 2014-2017, v.2, $8^{\circ}$ ano), concordamos que a afirmação feita por Santos e Curi (2010, p.32-33) perante a Proposta Curricular da década de 80 e 90 converge com os resultados de nossa pesquisa ao afirmar que "as abordagens relativas às fórmulas de figuras planas não se resumem em simples aplicação algébrica e sim há uma preocupação explicita de fazer com que o aluno tenha acesso aos significados envolvidos na construção de cada fórmula (...)".

\section{Considerações finais}

O Caderno do Aluno (SÃO PAULO, 2014-2017, v.2, $8^{\circ}$ ano) traz uma contextualização histórica e se inicia por esse conteúdo como assunto introdutório à abordagem do conceito de área de polígonos. Ao observar o estudo das áreas destaca-se o cuidado que esse material de apoio ao Currículo do Estado de São Paulo (SÃO PAULO, 2012) tem para desenvolver os conteúdos a partir da bagagem de conhecimento que o aluno vai adquirindo no decorrer do seu processo de aprendizagem.

Destaca-se no referido Caderno do Aluno a descrição das modificações figurais realizadas para obter a expressão para determinar a área dos polígonos, porém, o material proporciona uma única forma de modificação figural, a qual instiga o aluno a trabalhar com o paralelogramo; limitando o número de opções figurais para realizar outras modificações.

O Caderno do Aluno (SÃO PAULO, 2014-2017, v.2, $8^{\circ}$ ano) apresenta possibilidades para o desenvolvimento matemático do aluno. Na construção da área do trapézio esperase que a bagagem de conhecimento adquirida pelos alunos nas atividades experimentais realizadas, potencialize a capacidade de demonstrar a fórmula da área do trapézio.

No que diz respeito aos registros de representação semiótica, as atividades destacadas propiciam a aprendizagem dos alunos, pois atendem o pressuposto da teoria de Duval (2009) na qual os conceitos matemáticos só são acessíveis por meio da mobilização de pelo menos dois registros de representação semiótica e, à medida que o aluno consegue estabelecer relações entre os registros via tratamento e conversão, a aprendizagem se estabelece.

No que diz respeito à atividade semiótica de tratamento (transformação de representações realizadas dentro do mesmo registro), a análise do material revelou que o registro figural teve prioridade neste tipo de transformação. 
Em relação à conversão (mudança de um registro para o outro sem alterar os objetos matemáticos que estão em jogo), a maioria das atividades propostas, envolveu a conversão do registro figural para o registro na língua natural, algébrico, tabular ou numérico. Em termos de apreensão geométrica, para as atividades analisadas, a prioridade na mobilização e coordenação dos registros de natureza semiótica, foi com relação às modificações mereológica, óptica e posicional (modalidades da apreensão operatória).

\section{Referências}

BRASIL, Ministério da Educação. Parâmetros Curriculares Nacionais: Matemática. Brasília: MEC/SEF, 1998.

COBELLO, L. S.; OLIVEIRA, P. C. História e análise do currículo de matemática na escola básica no Estado de São Paulo. In: SIMPÓSIO INTERNACIONAL DE PESQUISA EM EDUCAÇÃO MATEMÁTICA, 4., 2015, Ilhéus. Anais... 12p. Ilhéus: UESC, 2015. CD-ROM.

DUVAL, R. Semiósis e pensamento humano: registro semiótico e aprendizagens intelectuais (Sémiosis et Pensée Humaine: Registres Sémiotiques et Apprentissages Intellectuels). Tradução de Lénio Fernandes Levy e Marisa Rosâni Abreu da Silveira. São Paulo. Editora Livraria da Física, fascículo I, 2009.

Ver e ensinar a matemática de outra forma: entrar no modo matemático de pensar os registros de representações semióticas. Organização Tânia M.M. Campos. Tradução de Marlene Alves Dias. São Paulo: PROEM, 2011.

Abordagem cognitiva de problema de geometria em termos de congruência. Traduzido por Méricles Thadeu Moretti., v.7, n.1, p. 118-138, 2012.

Rupturas e omissões entre manipular, ver, dizer e escrever: história de uma sequência de atividades em geometria. In: BRANDT, C. F.; MORETTI, M. T. (orgs). As contribuições da teoria das representações semióticas para o ensino e pesquisa na educação matemática. Ijuí: Editora Unijuí, 2014, p. 15-38.

ONUCHIC, L. R. de la; ALLEVATO, N. S. G. Pesquisa em Resolução de Problemas: caminhos, avanços e novas perspectivas. Bolema, v. 25, n. 41, p. 73-98, 2011.

SANTAELLA, L. O que é semiótica. São Paulo: Brasiliense, 2002.

SANTOS, C. A. B. dos; CURI, E. Proposta Curricular de Matemática: uma análise da relação institucional esperada para as noções de área e perímetro. REnCiMa, v. 1, n. 1, p. 27-33, 2010.

SÃO PAULO, Secretaria da Educação. Coordenadoria de Estudos e Normas Pedagógicas. Proposta Curricular para o Ensino de Matemática: ensino fundamental. $5^{\text {a }}$ ed. São Paulo: SE/CENP, 1997.

Proposta Curricular do Estado de São Paulo: Matemática. Coordenação de Maria Inês Fini. São Paulo: SEE, 2008.

Currículo do Estado de São Paulo: Matemática e suas tecnologias - Ensino Fundamental (Ciclo II) e Ensino Médio. Coordenação de área: Nilson José Machado. $1^{\text {a }}$ 
ed. atual. São Paulo, SEE, 2012.

Material de apoio ao Currículo do Estado de São Paulo - Caderno do

Professor: $8^{\circ}$ ano do Ensino Fundamental, Matemática. São Paulo: SEE, 2014-2017, v.2.

Material de apoio ao Currículo do Estado de São Paulo - Caderno do

Aluno: $8^{\circ}$ ano do Ensino Fundamental, Matemática. São Paulo: SEE, 2014-2017, v.2. 